\title{
What works in fraud prevention: a review of real-world intervention projects
}

\author{
Tim Prenzler
}

\begin{abstract}
Purpose - The purpose of this paper is to report on a search of criminology and related databases to identify fraud prevention intervention projects that showed promising achievements in reducing offences.

Design/methodology/approach - A keyword search of Criminal Justice Abstracts was supplemented by searches of related databases and case study repositories - conducted up to 31 May 2019. The paper includes some attention to indicators of "what doesn't work" as well as "what might work" or "what should work". Selection criteria were open about evidence, rather than exclusively applying strict scientific standards.

Findings - Overall, the literature is marked by inferences regarding what should work, based on diagnostics about opportunity factors in fraud and victim characteristics. In terms of evaluated intervention projects, only two were identified that met best practice scientific standards. However, a further 17 projects were included where there was some evidence of a likely benefit.

Research limitations/implications - Available evaluations of intervention projects are predominantly within-in group studies. Pre- and post-intervention time frames are often short, limited to one year or less; with only one follow-up study.

Practical implications - The findings demonstrate the need for applied experiments to build knowledge about effective fraud reduction strategies. The main lesson from the content of the 19 projects concerns the value of a situational crime prevention framework for designing and testing interventions, especially through enhancing rule setting, reducing anonymity, extending guardianship and formal surveillance, and facilitating compliance.

Originality/value - This appears to be the first systematic literature review of applied counter-fraud intervention projects.
\end{abstract}

Keywords Literature review, Case studies, Fraud, Situational crime prevention, Fraud prevention, Extending guardianship, Situational fraud prevention

Paper type Research paper

\section{Introduction}

In official terms, fraud involves obtaining a benefit illegally by deception. It appears as the main area of crime internationally that has gone against the trend of declining rates since the turn of the century (Prenzler, 2017a; PWC, 2018). The reasons for this appear to relate primarily to the ongoing growth of the internet and the means it provides to deceive victims from a distance. At the same time, many more traditional types of fraud continue to occur at high volumes - including deceptive advertising, Ponzi and pyramid schemes, insider trading, procurement fraud, embezzlement and much more (Prenzler, 2017a; PWC, 2018). Fraud also often continues to account for the largest category of crime in terms of direct financial losses to victims in many jurisdictions (Prenzler, 2017a; Warrell, 2017).

Given the size and growth of the fraud problem, it would be reasonable to expect a large number of well-documented intervention studies aimed at demonstrating successful anti-fraud strategies. However, this does not appear to be the case. The fraud literature has been characterised by descriptive statistics of the dimensions of the problem, and analyses of victim and offender characteristics and opportunity factors, with very little on prevention, especially in terms of applied projects (Prenzler, 2017a). Numerous guides and models for prevention have been produced, mainly based on reported industry innovations and practices which are
Tim Prenzler is based at the School of Law and Criminology, The University of the Sunshine Coast, The Sunshine Coast, Australia.
Received 9 April 2019 Revised 8 June 2019 Accepted 10 June 2019 
potentially very useful but often involve limited information and no systematic evidence. A common approach of inferring preventive strategies from risk factors or facilitative factors is shown in the quotation below related to internal prevention measures in businesses and government agencies (Sakurai and Smith, 2003, p. 6):

[...] organisations need to employ effective means of detecting anomalies, especially in dealing with identity-related fraud and computer fraud. Adequate ongoing personnel monitoring and supervision and ensuring that a high ethical culture exists within an organisation are also key ways in which fraud risk may be reduced. Internal controls need to be coupled with effective education of staff to improve fraud awareness and to understand that dishonesty within the workplace is unacceptable. Finally, ongoing re-assessment of risks is necessary in order to design appropriate counter measures suitable for our fast-changing society.

Interviews and surveys with counter-fraud practitioners have also been important for developing promising prevention measures in areas such as whistleblower support, procedural checks, auditing and employment screening (Tunley et al., 2018).

In addition to such approaches, there have been a number of assessments of predictive software, based largely on offence profiles and anomalous activities, aimed at proactively detecting fraud or attempted fraud and shutting it down (Khattri and Kumar Singh, 2018). These digital applications appear as the main area of innovation in fraud prevention, especially in commercial settings. However, there is very little information available publicly, possibly because of commercial-in-confidence provisions. Some experimental simulations have been published, which show the potential of particular commercial systems, but without clear evidence of the prevention of fraud in real-world settings (Kamps and Kleinberg, 2018; Khattri and Kumar Singh, 2018; Sakurai and Smith, 2003; Singh et al., 2013).

The literature also includes assessments of the impact of specialist agencies and teams, either in police departments or other public service sectors, or specialist inter-jurisdictional coordinating bodies for fraud. Despite the positive messaging and large financial investment in these agencies, there appears to be very little evidence of reductions in victimisation from their actions (e.g. Gillbert and Wakefield, 2018; Prenzler, 2017a; Quirke, 2010).

An additional area of reporting concerns cultural change (Sakurai and Smith, 2003). There are some indicators that attitudes and habits can be modified within organisations, through progressive leadership styles and improved supervision for example, in ways that enhance resistance to fraud (Ohalehi, 2019; Suh et al., 2019, 2018; Schuchter and Levi, 2016). For example, a survey of managers and supervisors in small and medium businesses in Malaysia found that a "culture of honesty and high integrity, anti-fraud processes and controls and appropriate oversight functions (have) a positive and significant effect on fraud prevention mechanisms" (N'Guilla Sow et al., 2018, p. 499). Similarly, a Dutch study surveyed police officers about the relationship between their colleagues' violations of ethical standards, including internal fraud and their perceptions of their supervisor's leadership style. Perceptions about leaders' "strictness" in relation to rule enforcement appeared to be "particularly effective in controlling fraud, corruption and the misuse of resources" (Huberts et al., 2007, p. 587).

Overall, many of the findings from studies like those outlined above have supported the case for the application of a situational crime prevention framework for designing counter-measures that have the best prospect of success in closing off or reducing opportunities in the settings in which fraud occurs (Tunley et al., 2018). From that perspective, the best guide is the matrix of 25 situational techniques across the five dimensions of "increase effort, increase risks, reduce rewards, reduce provocations and remove excuses", with techniques within these categories such as "extend guardianship", "reduce anonymity" and "assist compliance" (Cornish and Clarke, 2003, p. 90). Examples related to fraud include "increasing the effort" with more thorough checks on qualifications and background checks in employment processes, "rule setting" regarding strict identification requirements in applications for credit or bank accounts, "posting instructions" and "alerting conscience" in terms of communication about laws and penalties against fraud, "reducing rewards" through recovery of misappropriated assets, and "assisting compliance" through forms and procedures that reduce frustration and temptations to cheat (Prenzler, 2016; Tunley et al., 2018). 


\section{Method}

As noted in the above literature review, there have been numerous diagnostic and some simulation studies of fraud that provide potentially useful lessons which can be implemented in practice and tested in various ways. However, for the present study it was decided to follow-up on the issue of "real-world" intervention case studies (Kamps and Kleinberg, 2018, p. 9). These have the potential to provide valuable tests of the impacts of preventive strategies because they are likely to be affected by factors that cannot be accounted for by other approaches. The capacity of applied case studies to provide in-depth information about human agency, legal issues and complications in implementation is captured in the concepts of "realist evaluation" (Pawson and Tilley, 2004) and "process tracing" (Blatter and Haverland, 2014). Replication studies and follow-up studies can also provide further validation or modifications in knowledge about what works or is likely to work in practice.

Case study projects can be deliberate, usually with built in evaluation processes, or natural experiments, often with post hoc evaluation procedures. Although the randomised controlled study with statistical tests is seen as the "gold standard" of evaluation (Farrington et al., 2002), some of the best crime prevention studies in the literature have been natural experiments that lacked matched control groups (Clarke, 1997). "Within group" studies can be seen as having validity if the finding of efficacy related to the intervention appears as the best fit on the available evidence (Pawson and Tilley, 2004). At the same time, case studies will ideally include a variety of measures to optimise triangulation - such as offending rates, stakeholder surveys and financial cost-benefit data - with substantial pre- and post-implementation periods of several years and checks for displacement (Bates et al., 2017). Model intervention projects should also include preintervention diagnostics and consultation with stakeholders, and a justice-oriented focus to ensure that interventions are not oppressive nor discriminatory (Bates et al., 2017).

With the above in mind, it was decided to conduct a systematic search of the fraud literature carried out in February and March 2019 - for studies reporting on real-world prevention initiatives up to December 2018. The process was updated in early June to bring the search period up to 31 May 2019. The preference was for studies with multiple pre- and post-intervention indicators and comparison sites, but consideration was also given to within group studies with single measures of impact. An initial search was conducted of the main criminology database Criminal Justice Abstracts (EBSCOhost) using "fraud" and "prevent" as subject terms, with a wide net cast that included magazine articles and conference papers. This yielded 366 publications with abstracts. A scan was then conducted of the abstracts to identify publications that appeared to fit the above criteria. This reduced the yield to 16 . Full texts of 14 of these papers were obtained and assessed, with a final list of three studies of five projects considered within the criteria. Additional searches were then conducted using a variety of databases, including Criminal Justice Database and ABI/ INFORM (ProQuest) and ACCOUNT (Informit), Business Source Complete (EBSCOhost); and four crime prevention case study repositories: Crime Solutions (crimesolutions.gov), Center for Problem-Oriented Policing (popcenter.asu.edu), College of Policing (whatworks.college.police.uk/ Research/overview/Pages/default.aspx) and The Campbell Collaboration (campbellcollaboration. org). The content and reference lists of full text copies obtained through these searches were also used to identify potential studies. The second process yielded a further 18 studies, including some partial studies, making for a total of 24 evaluation reports covering 19 projects.

\section{Findings}

The search results are reported below in terms of projects in order of the year of publication of the main evaluation study. This format shows the infrequency of studies, the first dating to 1967, with little in the way of increasing numbers of studies over time. Overall, there were very few evaluated intervention projects identified by the standard search methods adopted in this paper. The results are particularly poor given the open criteria employed, and a number of studies are included with only the most limited indicators of positive impacts. The projects are listed under a brief heading related to the type of fraud that was targeted. The summaries include as much detail as possible about the mechanics of the interventions and evaluation methods and results, with further information provided in the theoretical critique in the subsequent discussion section titled "Implications". 


\section{Tax fraud}

The first study, by Schwartz and Orleans (1967), involved a randomised controlled trial in the area of suspected tax fraud, conducted through the United States Internal Revenue Service. One month before submitting their tax returns, in the guise of an interview about attitudes to tax, a "sanctions" intervention group $(n=89)$ was given information about penalties for tax fraud, a "conscience" group $(n=92)$ received information on moral arguments against fraud and a "placebo" group ( $n=92)$ was given a neutral interview. The official tax returns of these groups were compared to those of an "untreated" control group $(n=111)$. The results involved complex variations between groups across reported income and deductions, involving a variety of statistical tests. However, the main finding identified by the researchers was that the "conscience" group submitted the highest income returns on average in comparison to the control group (+US\$804), the "sanctions" group the next highest (+US\$181) and the "placebo" group the least high (+US\$81), leading to the conclusion that "compliance can be increased by threat of punishment" and "appeals to conscience can be a more effective instrument than sanction threat for securing compliance" (p. 299).

\section{Cheque fraud}

Knutsson and Kuhlhorn (1997, first published 1981) assessed the impact of a new (unspecified) identification requirement for cashing cheques in Sweden in 1971. Recorded "cheque crimes" fell 81 per cent from 39,337 in 1970 to 7,315 in 1972. In Stockholm, offences fell 86 per cent from 15,817 to 2,198 in the same period. These reductions were sustained over the following six years of recorded data.

\section{Welfare fraud}

Kuhlhorn (1982) reviewed the effects of a computerised data-matching programme applied to housing subsidies in Sweden in 1979. Automated checks identified discrepancies between income estimates in two databases: applications for housing subsidies (the target area) and for sickness insurance. In the first case, applicants were motivated to understate their income with a view to increasing their subsidy, and in the second they were motivated to overstate their income to increase their benefit. In the first year of activation, 39,408 households lost all or part of their subsidy (6.1 per cent of checked households). Awareness of the system also motivated a large number of voluntary corrections.

\section{Welfare fraud}

Greenberg et al. (1986) examined the impact of a computer-based "wage-matching" system introduced in 1982 in four US counties for clients on food stamp and family support programs. Client-reported incomes were compared against employer-reported wages. The findings across the four sites covered an approximate 12-month period mainly over 1982. The study included financial cost-benefit data, with benefits estimated at approximately twice the costs: input costs were put at US $\$ 2.2 \mathrm{~m}$ and savings through recoveries and reduced payments were put at US $\$ 4.3 m$ ( $p$. 166). The focus of the intervention was reportedly on payment corrections, but with prosecutions for more serious cases of fraud (see also Greenberg and Wolf, 1985).

\section{Credit fraud}

Levi et al. (1991) reported on an initiative of the Consumer Credit Trade Association in the UK called the Credit Industry Fraud Avoidance System, involving major building societies and banks. Association members shared details of confirmed and suspected fraud cases. Where applications showed a match, the agencies engaged in further investigations before denying or approving an application. According to the researchers, "this exercise in data sharing does appear to be bearing dividends" (p. 14):

During 1990, CIFAS identified 6,991 fraudulent applications, of which over 1,000 involved innocent parties whose identities were being "borrowed" to add credibility to the application. The average value of all fraudulent applications was $£ 1,505$. At a cost of some $£ 80,000$ to members, CIFAS saved 
$£ 10.5$ million in fraud. During the first quarter of 1991 , the net saving to members was over $£ 4.5$ million, reflecting the escalating level of application frauds as well as a new category of rejected attempted fraudulent applications with which CIFAS now deals.

The report highlighted outcomes from a firm which issued credit cards. Within six months of joining the alert system, 1,275 of 88,000 applications were rejected on the basis of warning flags, saving an estimated £2,600 per case, making for a total of $£ 3,315,000$, at an input cost of just £350.

\section{Card fraud}

Levi et al. (1991) also reported on a 1986 initiative by Midland Bank called "Check Card" to counter the fraudulent use of stolen cards. The system involved 20 members entering information about stolen and missing cards into a shared database accessible by telephone by sales assistants with suspicions about a card. The system was hampered by large numbers of calls about cards issued by non-members, slowing down call times. However, over a nine-month period in 1990, once the scheme was fully operational, of 14,000 calls related to member cards, 1,260 , or 9 per cent, were flagged as missing or stolen. Rejections resulted in savings of approximately $£ 500$ per card, making for a total of $£ 630,000$, for an input cost of $£ 50,000$.

\section{Card fraud}

Masuda (1993) evaluated the introduction in 1992 of an "early warning system" for potential credit card fraud by Tops Appliance City - an electrical goods retailer in the USA. Tops trained sales staff in the modus operandi and profile of retail fraudsters, drawing on advice from outside experts. Indicators included disregard for price, multiple purchases at the same time and not using a wallet or purse. Suspicions were reported to security staff who would discreetly track suspects, including via video, and seek further information about them, such as the presence of accomplices. The process from there, as described, was somewhat ambiguous. However, it essentially involved an intervention by security staff at the point of sale, apparently frequently leading to referrals to police. Of note was the fact that employees who reported fraudulent cards received a cash reward. Masuda (1993, p. 131) reported the main findings as follows:

The number of fraud incidents reported for 1992 was more than two-and-a-half times greater than the number reported for 1991. On the other hand, losses sustained by the Tops' proprietary card decreased 78\%, from just over US\$800,000 in 1991 to US\$170,000 for the first ten months of 1992. In addition, reported Visa and Mastercard losses at Tops decreased 90\% from US $\$ 313,000$ in 1991 to nearly US\$40,000 for the first ten months of 1992.

A deterrent "diffusion of benefits" effect was also apparent in reductions in money order and cheque fraud (p. 133).

\section{Refund fraud}

Challinger (1996) examined the effect of a "proof of purchase" requirement to stop refund fraud in the retail sector. In 1993, Coles Myer in Australia introduced a requirement for evidence of purchase, mainly through provision of a receipt, before refunds would be issued. Data were collected for nine months before the policy was introduced and 16 months following, across 961 stores. Business confidentiality prevented the author from publishing exact numbers for incidents. However, indicative data showed an 83 per cent reduction in "detected refund frauds" and a 63 per cent reduction in financial losses over the longer term (Challinger, 1997).

\section{Card fraud}

Webb (1996) reported on the implementation by banks in the UK of recommendations from the Levi et al. (1991) study above by the Home Office Crime Prevention Unit. Webb provided very brief descriptions of four initiatives to stop "plastic card fraud": (1) increasing the value of transactions requiring "bank authorisation", which grew from approximately 11 per cent of transactions before 1992 to 45 per cent by 1996, (2) a "hot card file" for rapid communication about stolen and lost cards, reducing direct mailing of cards, (3) including using couriers and 
collection at branches, and (4) a "Card Watch" publicity campaign to encourage better security measures by cardholders (p. 24). Webb used data from the Association for Payment Clearing Services to show that losses from card fraud peaked in 1991 at $£ 165.5 \mathrm{~m}$. The above measures were largely in place by 1992. Over six years losses fell to £96.8m in 1994 ( -41.5 per cent). Within these figures, losses at sales points declined by 49 per cent and losses associated with cards stolen from the post declined by 62 per cent (p. 25).

\section{Pay phone toll fraud}

Bichler and Clarke (1996) described efforts to stop "pay phone toll fraud" in Manhattan's Port Authority Bus Terminal. The fraud involved organised crime groups obtaining international access numbers and selling these to callers. The numbers were acquired by covert observation of callers and by hackers who stole numbers from businesses. The fraud attracted large numbers of callers and created disorder problems within the terminal. Management first analysed the crime problem using systematic observations and commuter surveys. Experiments were conducted with roping off "hot spot" locations and blocking international access on phones. These methods were too inconvenient or were bypassed by the fraudsters. A consulting firm was then engaged to develop more sophisticated software to block all international calls, including those made through exclusive company numbers, leaving the phones free for the large bulk of commuters making local or interstate calls. Following installation, "fraudulent activity disappeared and there was a dramatic improvement in the atmosphere of the building" with "few complaints" (Bichler and Clarke, 1996, p. 105). The evaluation found evidence of partial displacement, which was then curbed in these locations through the adoption of similar measures.

\section{Insurance fraud}

Blais and Bacher (2007) conducted an experiment in Canada to test the impact of warning letters against suspected insurance fraud in the form of "claim padding". Customers making claims for residential theft were randomly assigned to two groups. A control group received the normal letter of response, while the experimental group received letters and claim forms that included warnings that claim padding was a criminal offence and that the company was committed to prosecuting offenders. There was also an appeal to conscience. The study, involving four companies and 765 claims, was conducted with the assistance of the Insurance Bureau of Canada. The main finding was that claims made by the experimental group were on average $\mathrm{C}$ $\$ 311.11$, or 11 per cent, less than those in the control group (C\$2,469.73 vs C\$2,780.84), and this was attributed to the deterrent effect of the warnings.

\section{Card fraud}

Levi (2008) assessed the impact of the "Chip and PIN" security system on plastic cards in the early-2000s in the UK. The system replaced the dominant signature and magnetic stripe system which was increasingly vulnerable to card theft, forged signatures and "cloning" and "skimming". In the UK, the full roll out of Chip and PIN, from the latter part of 2003, entailed companies issuing $140 \mathrm{~m}$ cards to $42 \mathrm{~m}$ clients, along with upgrades to hundreds-of-thousands of ATMs and retail terminals. The study examined two years of data across several categories of card transactions. For the UK, losses from cards stolen from letters fell by 81 per cent from $£ 79.9 \mathrm{~m}$ in 2004 to $£ 15.4 \mathrm{~m}$ in 2006. In "face-to-face" retail transactions involving cards issued in the UK, losses fell by 67 per cent from $£ 218.8 \mathrm{~m}$ to $£ 72.1 \mathrm{~m}$ in 2006. At the same time, victimisation of UK cardholders in other countries without Chip and PIN increased by 43 per cent.

\section{Medicaid fraud}

Fischer (2014) documented the introduction in 2011 of "inventory reviews" conducted on pharmacies by the New York Office of the Medicaid Inspector General. The reviews compared Medicaid funded sales of medicines with pharmacists' wholesale purchases to guard against the sale of medicines purchased on the black market - often including substandard and dangerous batches. A major test case shut down a scam operating out of one pharmacy involving US $\$ 1.8 \mathrm{~m}$ of false claims over 12 months. This success led to an enlarged programme of 
deterrent oriented reviews. A 2015 report associated a wider programme of "audit fieldwork" in Medicaid in New York with US\$3.7m of recovered overpayments (New York State Office of the State Comptroller, 2015, p. 7).

\section{Predatory lending}

Ager Caplan (2014) described a number of strategies adopted by community-based action groups and social workers in the USA to prevent the victimisation of vulnerable low-income groups from "predatory financial services", including "payday lenders" who overstate customers' capacity to repay loans. Strategies included assisting persons to set up bank accounts and obtain finance at normal rates; creating localised banking collectives, "lending circles" and charity funds that provide flexible loans; and engaging in campaigns to educate communities, including naming predatory lenders, and to change regulations and increase affordable housing funds. Ager Caplan's (2014) account includes the example of lobbying by the Association of Community Organizations for Reform Now (ACORN) which led in 2002 to a group of states attorneys general initiating a successful class action against a predatory lending firm (Hurd and Kest, 2004). The settlement entailed an undertaking by the company to improve their lending practices. A subsequent settlement included a US $\$ 72 \mathrm{~m}$ "Foreclosure Avoidance Program" involving reductions in interest rates and principals, and waivers of late fees (ACORN News, 2003). The latter helped "ameliorate" the harm done to victims (Ager Caplan, 2014, p. 149).

\section{Online fraud}

Cross (2016) reported on the operations of "Project Sunbird", an initiative of the Western Australia Police and Department of Commerce to prevent repeat online fraud, particularly in the areas of "advance fee fraud" and "romance scams" perpetrated from West Africa. The two main elements of the project involved using "financial intelligence" systems to flag account holders with suspicious financial transactions and sending letters to these customers warning them they might by victims of scams and providing contacts for assistance. An initial phase flagged AU $\$ 17.9 \mathrm{~m}$ of transactions. Between March 2013 and October 2015, 3,001 warning letters were sent. Subsequently, 73 per cent of recipients stopped sending money over a three-month period, and 13 per cent reduced the amount of money. A further 1,503 follow-up letters were sent. Of this group, 53 per cent stopped sending money and 27 per cent reduced the amount.

\section{Online fraud}

Cross (2016) also reported on "Project Disrepair", operated by the South Australia Police, which replicated many of the features of Project Sunbird (above). A total of 1,301 first warning letters were sent over an approximate two-year period from 2013 to 2015, with 254 follow-up letters. The limited data available showed that 76 persons stopped sending money.

\section{Online fraud}

Cross (2016) reported on a third project: the "National Scams Disruption Project" initiated by the Australian Competition and Consumer Commission. The project also targeted the transmission of money to suspected West African scammers, and copied the main features of Project Sunbird (above). Over a period of approximately one year, from 2014 to 2015, 4,700 letters were sent, including 874 follow-up letters, involving AU\$61m in suspicious transactions. The main finding was that, "of those who received a first letter, 77 per cent have not sent money to any overseas jurisdiction for a follow-up period of six weeks or more" (p. 134).

\section{Welfare fraud}

Prenzler (2016) reported on a two year follow-up study of an "early intervention" system developed by Australia's Centrelink agency to pre-empt welfare clients' drift into fraud through non-reporting of assessable changes in their circumstances (Prenzler, 2017b). Examples of reportable conditions include employment, enrolment status in an educational institution and co-habitation. From 2011to 2012, Centrelink began using SMS messaging and personal phone 
calls to remind clients of their legal obligation to disclose changes. Centrelink reported that over 120,000 contacts were made under this "front-foot initiative" in an initial five-month period, with an estimated saving of AU\$37m (Prenzler, 2016, p. 197). Over five years, the official number of fraud cases referred by Centrelink to the public prosecutor reduced by 80 per cent, from a high of 5,312 in 2007-2008 to a low of 1,071 in 2013-2014. A six-year interrupted time series analysis showed a sustained reduction in the rate of convictions of 83 per cent - as a proportion of clients - and a reduction in associated financial losses of 60 per cent - from an average AU\$41.2bn per annum to AU\$16.7bn.

\section{Medicare and medicaid fraud}

Leventis (2016) described a shift in anti-fraud measures by the Centres for Medicare and Medicaid Services (CMS) in the USA, from a "pay-and-chase" strategy - involving retrospective investigations and attempted recoveries of fraud - to a "prevention-and-detection" strategy based on identifying and stopping attempted fraud before payments were made. The new measures involved a "twin pillar" approach, introduced in 2011. The first pillar - referred to as the "Fraud Prevention System" (FPS) - involved the application of multiple algorithms to flag aberrant claims by health providers. These were then investigated by "boots-on-the-ground" methods, including "site visits, beneficiary interviews, and medical records reviews" (p. 31). The outcomes could entail denial of payments, suspension of billing rights and referrals for prosecution. The second pillar - referred to as the "Automated Provider Screening" (APS) system - involved a continuous checking process for new and current service providers utilising multiple data sources including criminal records and FPS outcomes (the first pillar above). Leventis (2016) used CMS reports to Congress to assess the impact of these initiatives (p. 32):

CMS asserted that the FPS has saved the Medicare program approximately $\$ 820$ million over the first three years of its existence (2012-2014). It further identified \$454 million in savings associated with the prevention-and-detection actions of the FPS and APS systems during 2014 (either directly via stopped payments or indirectly through investigations from FPS leads). According to CMS's statistics, the program yielded a nearly 10:1 dollar return on investment, with the majority of savings due to new leads or issues identified by the FPS. (cf. Centers for Medicare and Medicaid Services, 2016)

However, Leventis (2016, p. 32) noted that the Office of the Inspector General of the Department of Health and Human Services disputed these claims, based on "actual" rather than "projected" savings, arguing that savings were more likely in the ratio 2.84:1 in 2014 with US\$133.2m of actual savings (Office of Inspector General, United States Department of Health and Human Services, 2015, p. 14).

\section{Implications}

The first and most obvious point to make from the outcomes of this study is how few evaluations of real-world projects have been published which are accessible through standard academic search mechanisms. The paucity of findings stands in stark contrast to the growing size of the fraud problem globally; and this problem is exacerbated by the age of many of the studies included herewith just over half the papers published before 2001. The most important implication therefore is that there needs to be a much stronger commitment to experiments in prevention by government agencies and the private sector, and to sharing knowledge and engaging in further testing of what appears to be beneficial. The initial literature review for this study referred to initiatives in commercially available predictive software, specialist government anti-fraud agencies and protective corporate cultures (e.g. Gilbert and Wakefield, 2018; Khattri and Kumar Singh, 2018; Schuchter and Levi, 2016). However, in most cases, the studies included in the detailed Findings section showed how slow public and private sector organisations are to experiment with innovations to combat fraud or to share results (cf. Ruimschotel, 1993). It may be the case that private sector organisations are often under the misapprehension that procedural changes, such as identification requirements, will alienate customers (Challinger, 1997; Knutsson and Kuhlhorn, 1997). For example, in the case of the Swedish cheque fraud study, the problem reached epidemic proportions before companies acceded to police pressure to introduce proof of identity requirements. However, the example of financial institutions in the UK implementing 
recommendations from a Home Office fraud assessment report, with a subsequent evaluation, is a particularly useful example of the potential benefits of government research and engagement with the private sector (Levi et al., 1991; Webb, 1996).

Many of the projects reported on in the present study involved public sector organisations with higher standards of accountability than commercial entities, with greater obligations to protect public resources and protect vulnerable persons. These included police, taxation, welfare and consumer protection agencies; however, none appeared to have a commitment to maintaining, extending and reporting on innovations that showed success. This is despite the strength of public opinion against fraud and in support of preventive practices - even those that can be seen as intrusive (e.g. Kuhlhorn, 1982). In the case of the welfare fraud reduction project in Australia (Prenzler, 2016), the responsible agency was repeatedly criticised for putting increasingly large numbers of low-level offenders through the criminal courts - a majority of whom were women living in poverty - before it lost a crucial test case on evidentiary grounds. The case forced it to shift from a simplistic prosecution policy to a prevention focused approach (Prenzler, 2016).

Another major adverse finding from the present review concerned the very small number of studies with a full experimental design. Only two reports met these criteria: those by Schwartz and Orleans (1967) and Blais and Bacher (2007) concerning warnings to potential offenders about sanctions and alerting social conscience. The main drawback with these studies, however, was that they tested for suspected fraud - against normative standards for tax returns and insurance applications - rather than proven fraud or other more objective measures of fraud. The findings were highly promising nonetheless. The Australian study of very large and sustained reductions in official rates of welfare fraud lacked a matched control group but found that the Australian case appeared to be unique when compared to official welfare fraud rates internationally, mainly in the USA and UK (Prenzler, 2016, p. 191). At the same time, the issue of causality was complicated in this case by the possibility that the reduction in offences associated with the mass communication initiative was also influenced by a change towards a much more cautious prosecution policy.

The studies examined in the paper were problematic in a number of other ways. Only four included financial cost-benefit data: the welfare fraud "wage-matching" study from the USA (Greenberg et al., 1986), the two UK data-sharing early warning projects (Levi et al., 1991) and the Medicare/Medicaid early warning system in the USA (Leventis, 2016). Although not an essential requirement, crime prevention projects will ideally show financial savings that exceed the cost of the innovation, as appeared to be the case with these projects. Another issue concerned the lack of follow-up studies to test the longer-term effects of interventions. Only the Australian welfare fraud study involved a follow-up assessment, which appeared to at least partially confirm the ongoing value of the early warning system (Prenzler, 2016). At the same time, this study was conducted using open source material, without the co-operation of the agency involved, and the study noted the lack of detail about the programme essential to public accountability. Ager Caplan's (2014) description of community-based victim support programs and a litigation case also was extremely short on detail and, overall, she emphasised that there was a lack of evidence of success in these programs.

Despite these problems, there do appear to be some valuable take away messages from the 19 projects reported on here. The limited findings support the view from the literature that the 25 techniques of situational prevention provide the best guide for diagnosing fraud opportunities and designing and evaluating interventions (Tunley et al., 2018). The tax fraud study (Schwartz and Orleans, 1967), the insurance fraud study (Blais and Bacher, 2007) and the welfare fraud study (Prenzler, 2016) supported the situational techniques of deterring offending through "rule setting", "posting instructions", "removing excuses" and "alerting conscience". The welfare fraud study also showed the value of "assisting compliance" through personal communication about how to register changes in eligibility for payments.

The idea of communicating warnings also applied to potential victims, as shown in Cross's (2016) review of three Australian projects involving interventions in fraudulent online communications. This involved preventing ongoing fraud, or repeat victimisation, and could be categorised in situational terms as "extending guardianship" and "strengthening formal surveillance". 
The various data matching, offender profiling and early warning projects also fitted in these categories (Bichler and Clarke, 1996; Fischer, 2014; Greenberg et al., 1986; Leventis, 2016; Levi et al., 1991; Masuda, 1993; Webb, 1996). In that regard, predictive software which facilitates early intervention against attempted or embryonic fraud would appear to be a major area of likely future benefit (cf. Khattri and Kumar Singh, 2018). Ager Caplan's (2014) account of a community-based group assisting potential victims to avoid predatory lending also involved "extending guardianship". The additional idea in her study of ameliorating losses to victims through financial redress from offenders could be partially categorised in situational terms as "reducing rewards". In terms of social justice dimensions of fraud prevention, some constructive findings were also notable in offender-oriented interventions where the focus was placed on payment corrections for potential welfare fraud offenders rather than criminal prosecutions (Greenberg and Wolf, 1985; Kuhlhorn, 1982; Prenzler, 2016).

The potential value of "rule setting" and "controlling access" was also shown in the studies on enhanced identification requirements, including the refund fraud study (Challinger, 1996), cheque cashing study (Knutsson and Kuhlhorn, 1997) and Chip and PIN study (Levi, 2008). The Chip and PIN strategy required the adoption of sophisticated technology, as did the data-matching strategies and early warning systems (e.g. Cross, 2016; Leventis, 2016). In contrast, the refund fraud study, involving provision of a receipt, and the face-to-face identification requirement for cashing cheques, showed how fairly simple requirements can dramatically reduce fraud in some circumstances. In the Swedish cheque study, the researchers first described how the orthodox official response to cheque fraud involved complex, expensive and largely ineffective police investigations and prosecutions. This was replaced by "an inexpensive and effective situational control" centred on reducing anonymity (Knutsson and Kuhlhorn, 1997, p. 116). Data matching is also a very simple procedure but one that requires computerisation to be conducted on a mass scale.

This is not to say that applying situational measures always provides quick solutions that can be set and forgotten. For example, Challinger (1996) identified partial adaptions by offenders to blocked opportunities, entailing some "tactical displacement" that needed to be addressed as an unintended consequence of the proof of purchase requirement (p. 257). Inventive adjustments included purchasing one item and stealing an identical item, then returning the stolen item using the receipt from the purchased item. Despite the reduction in card fraud identified by Levi (2008), following the introduction of Chip and PIN technology in the UK in 2003-2004, Finch (2011) identified displacement of card fraud to areas such as online transactions and fraudulently obtained cards that led to an overall increase in card-related fraud from 2005 to 2008.

\section{Conclusion}

This paper is the product of an international search for published studies of real-world interventions to prevent fraud, focused on case studies with indicators of success. The results were meagre. Only 19 projects were included, documented in 24 studies. The majority lacked model scientific controls, adequate pre- and post-intervention periods for data, and only four included financial cost-benefit data. Nonetheless, the available evidence from the studies supported the application of a situational prevention matrix to develop and trial fraud prevention strategies with the best chance of success. Overall, there is an urgent need for scientific studies of effective interventions against fraud.

\section{References}

ACORN News (2003), available at: http://comm-org.wisc.edu/commorgarchives/archives/colist/2003November/003087.html (accessed 30 February 2019).

Ager Caplan, M. (2014), "Communities respond to predatory lending”, Social Work, Vol. 59 No. 2, pp. 149-56.

Bates, L., Belsham, D. and Miles-Johnson (2017), “Crime prevention: setting standards”, in Prenzler, T. (Ed.), Understanding Crime Prevention: The Case Study Approach, Australian Academic Press, Brisbane, pp. 1-12.

Bichler, G. and Clarke, R. (1996), "Eliminating pay phone toll fraud at the port authority bus terminal in Manhattan", Crime Prevention Studies, Vol. 6, pp. 93-115. 
Blais, E. and Bacher, J. (2007), "Situational deterrence and claim padding: results from a randomized field experiment”, Journal of Experimental Criminology, Vol. 3 No. 4, pp. 337-52.

Blatter, J. and Haverland, M. (2014), "Case studies and (causal-) process tracing", in Engeli, I. and Rothmayr Allison, C. (Eds), Comparative Policy Studies, Palgrave Macmillan, Basingstoke, pp. 59-84.

Centers for Medicare and Medicaid Services (2016), US Department of Health and Human Services, available at: fraud-prevention-system-return-on-investment-fourth-implementation-year-2015.pdf (accessed 6 March 2019).

Challinger, D. (1996), "Refund fraud in retail stores", Security Journal, Vol. 7 No. 1, pp. 27-35.

Challinger, D. (1997), "Refund fraud in retail stores", in Clarke, R. (Ed.), Situational Crime Prevention: Successful Case Studies, Harrow and Heston, Guilderland, NY, pp. 250-62.

Clarke, R. (Ed.) (1997), Situational Crime Prevention: Successful Case Studies, Harrow and Heston, Guilderland, NY.

Cornish, D. and Clarke, R. (2003), "Opportunities, precipitators and criminal decisions", Crime Prevention Studies, Vol. 16, pp. 41-96.

Cross, C. (2016), "Using financial intelligence to target online fraud victimisation: applying a tertiary prevention perspective", Criminal Justice Studies, Vol. 29 No. 2, pp. 125-42.

Farrington, D., Gottfredson, D., Sherman, L. and Layton MacKenzie, L. (2002), "The Maryland scientific methods scale", in Sherman, L., Farrington, D., Welsh, B. and Layton MacKenzie, D. (Eds), Evidence-based Crime Prevention, Routledge, London, pp. 13-21.

Finch, E. (2011), "Strategies of adaptation and diversification: the impact of chip and PIN technology on the activities of fraudsters", Security Journal, Vol. 24 No. 4, pp. 251-68.

Fischer, W. (2014), "Innovations in fighting fraud: inventory reviews in New York", Journal of Government Financial Management, Winter, pp. 34-8.

Gilbert, M. and Wakefield, A. (2018), "Tackling fraud effectively in central government departments", Journal of Financial Crime, Vol. 25 No. 2, pp. 384-99.

Greenberg, D. and Wolf, D. (1985), "Is wage matching worth all the trouble?", Public Welfare, Winter, pp. 13-20.

Greenberg, D., Wolf, D. and Pfiester, J. (1986), Using Computers to Combat Welfare Fraud, Greenwood Publishing, Westport, CT.

Huberts, L., Kaptein, M. and Lasthuizen, K. (2007), "A Study of the impact of three leadership styles on integrity violations committed by police officers", Policing: An International Journal of Police Strategies and Management, Vol. 30 No. 4, pp. 587-607.

Hurd, M. and Kest, S. (2004), "Fighting predatory lending from the ground up: an issue of economic justice", in Squires, G. (Ed.), Organizing Access to Capital Advocacy and the Democratization of Financial Institutions, Temple University Press, Philadelphia, PA, pp. 119-34.

Kamps, J. and Kleinberg, B. (2018), "To the moon: defining and detecting cryptocurrency pump-anddumps", Crime Science, Vol. 7, pp. 1-18.

Khattri, V. and Kumar Singh, D. (2018), "Parameters of automated fraud detection techniques during online transactions”, Journal of Financial Crime, Vol. 25 No. 3, pp. 702-20.

Knutsson, J. and Kuhlhorn, E. (1997), "Macro-measures against crime: the example of check forgeries”, in Clarke, R. (Ed.), Situational Crime Prevention: Successful Case Studies, Harrow and Heston, Guilderland, NY, pp. 113-21.

Kuhlhorn, E. (1982), "Juggling with housing allowances: an example of prevention of crime in a welfare society”, in Kuhlhorn, E. and Svensson, B. (Eds), Crime Prevention, National Swedish Council for Crime Prevention, Stockholm, pp. 195-205.

Leventis, J. (2016), “Evaluating CMS's fraud prevention system”, Health Law, Vol. 28 No. 4, pp. 29-34.

Levi, M. (2008), "Combating identity and other forms of payment fraud in the UK", Crime Prevention Studies, Vol. 23, pp. 111-31.

Levi, M., Bissell, P. and Richardson, T. (1991), The Prevention of Cheque and Credit Card Fraud, Home Office Crime Prevention Unit, London.

Masuda, B. (1993), "Credit card fraud prevention: a successful retail strategy", Crime Prevention Studies, Vol. 1, pp. 121-34. 
N'Guilla Sow, A., Basiruddin, R., Mohammad, J. and Abdul Rasid, S. (2018), "Fraud prevention in Malaysian small and medium enterprises (SMEs)", Journal of Financial Crime, Vol. 25 No. 2, pp. 499-517.

New York State Office of the State Comptroller (2015), Medicaid Claims Processing Activity October 1, 2014 Through March 31, 2015, New York State Office of the State Comptroller, New York, NY.

Office of Inspector General (US Department of Health and Human Services) (2015), The Fraud Prevention System Increased Recovery and Prevention of Improper Medicare Payments, But Updated Procedures Would Improve Reported Savings, Office of Inspector General (US Department of Health and Human Services), Washington, DC.

Ohalehi, P. (2019), "Fraud in small charities: evidence from England and Wales", Journal of Financial Crime, Vol. 26 No. 1, pp. 211-22.

Pawson, R. and Tilley, N. (2004), "Realistic evaluation", in Matthieson, S. (Ed.), Encyclopaedia of Evaluation, Sage, Newbury Park, CA, pp. 362-7.

Prenzler, T. (2016), "Welfare fraud prevention in Australia: a follow-up study", Crime Prevention and Community Safety, Vol. 18 No. 3, pp. 187-203.

Prenzler, T. (2017a), "Fraud victimisation and prevention”, in Deckert, A. and Sarre, R. (Eds), The Australian and New Zealand Handbook of Criminology, Crime and Justice, Routledge, London, pp. 269-83.

Prenzler, T. (2017b), "Reducing welfare fraud: an Australian case study", Security Journal, Vol. 30 No. 2, pp. 569-84.

PWC (2018), "Global economic crime survey 2018", available at: www.pwc.com/gx/en/forensics/globaleconomic-crime-and-fraud-survey-2018.pdf (accessed 2 March 2019).

Quirke, B. (2010), "OLAF's role in the fight against fraud in the European Union: do too many cooks spoil the broth?", Crime, Law and Social Change, Vol. 53 No. 1, pp. 97-108.

Ruimschotel, D. (1993), "Ambiguities between criminal policy and scientific research", European Journal on Criminal Policy and Research, Vol. 1 No. 3, pp. 101-22.

Sakurai, Y. and Smith, R. (2003), "Identifying and responding to risks of serious fraud in Australia and New Zealand", Trends and Issues in Crime and Criminal Justice, No. 270, pp. 1-6.

Schuchter, A. and Levi, M. (2016), "The Fraud triangle revisited”, Security Journal, Vol. 29 No. 2, pp. 107-21. Schwartz, R. and Orleans, S. (1967), "On legal sanctions", The University of Chicago Law Review, Vol. 34 No. 2, pp. 274-300.

Singh, K., Best, P. and Mula, J. (2013), "Automating vendor fraud detection in enterprise systems”, Journal of Digital Forensics, Security and Law, Vol. 8 No. 2, pp. 7-41.

Suh, J., Nicolaides, R. and Trafford, R. (2019), "The effects of reducing opportunity and fraud risk factors on the occurrence of occupational fraud in financial institutions", International Journal of Law, Crime and Justice, Vol. 56 March, pp. 79-88.

Suh, J., Shim, H. and Button, M. (2018), "Exploring the impact of organizational investment on occupational fraud: mediating effects of ethical culture and monitoring control”, International Journal of Law, Crime and Justice, Vol. 53 June, pp. 46-55.

Tunley, M., Button, M., Shepherd, D. and Blackbourn, D. (2018), "Preventing occupational corruption: utilising situational crime prevention techniques and theory to enhance organisational resilience", Security Journal, Vol. 31 No. 1, pp. 21-52.

Warrell, H. (2017), "Fraud and online crimes make up almost half of UK's 11.8m total", available at: www.ft. com/content/03e8674e-de47-11e6-9d7c-be108f1c1dce (accessed 2 March 2019).

Webb, B. (1996), "Preventing plastic credit card fraud in the UK", Security Journal, Vol. 7 No. 1, pp. 23-5.

\section{Corresponding author}

Tim Prenzler can be contacted at: tprenzler@usc.edu.au

For instructions on how to order reprints of this article, please visit our website:

www.emeraldgrouppublishing.com/licensing/reprints.htm

Or contact us for further details: permissions@emeraldinsight.com 